\title{
Complement Inhibition as a Proposed Neuroprotective Strategy following Cardiac Arrest
}

\author{
Brad E. Zacharia, Zachary L. Hickman, Bartosz T. Grobelny, Peter A. DeRosa, \\ Andrew F. Ducruet, and E. Sander Connolly \\ Department of Neurological Surgery, Columbia University, 710 W. 168th Street, New York, NY 10032, USA \\ Correspondence should be addressed to Brad E. Zacharia, bez2103@columbia.edu
}

Received 13 May 2009; Revised 18 October 2009; Accepted 4 November 2009

Recommended by Fulvio D’Acquisto

Out-of-hospital cardiac arrest (OHCA) is a devastating disease process with neurological injury accounting for a disproportionate amount of the morbidity and mortality following return of spontaneous circulation. A dearth of effective treatment strategies exists for global cerebral ischemia-reperfusion (GCI/R) injury following successful resuscitation from OHCA. Emerging preclinical as well as recent human clinical evidence suggests that activation of the complement cascade plays a critical role in the pathogenesis of GCI/R injury following OHCA. In addition, it is well established that complement inhibition improves outcome in both global and focal models of brain ischemia. Due to the profound impact of GCI/R injury following OHCA, and the relative lack of effective neuroprotective strategies for this pathologic process, complement inhibition provides an exciting opportunity to augment existing treatments to improve patient outcomes. To this end, this paper will explore the pathophysiology of complement-mediated GCI/R injury following OHCA.

Copyright ( 92009 Brad E. Zacharia et al. This is an open access article distributed under the Creative Commons Attribution License, which permits unrestricted use, distribution, and reproduction in any medium, provided the original work is properly cited.

\section{Introduction}

A dearth of effective treatment strategies exist for global cerebral ischemia-reperfusion (GCI/R) injury following successful resuscitation from out-of-hospital cardiac arrest (OHCA). OHCA is a devastating disease process with neurological injury accounting for a disproportionate amount of the morbidity and mortality following return of spontaneous circulation (ROSC). The incidence of OHCA in industrial countries ranges from 0.04 to $0.13 \%$ of the total population per year, and only $11-48 \%$ of patients admitted to the hospital are discharged in good neurologic condition. At present, therapeutic hypothermia is the only neuroprotective strategy shown to be effective in well-controlled, prospective trials of OHCA.

Complement, an important component of the innate immune system, is known to play a central deleterious role in multiple diverse disease processes. Eculizumab, a monoclonal C5-antibody, is currently being used to treat paroxysmal nocturnal hematuria, and pexelizumab, also a C5-antibody, has been studied as adjunctive therapy in ischemic heart disease $[1,2]$. Emerging preclinical as well as recent human clinical evidence also suggests that activation of the complement cascade plays a critical role in the pathophysiology of GCI/R injury following OHCA [3]. In addition, it is well established that complement inhibition improves outcome in both global and focal models of brain ischemia [4-8]. Due to the profound impact of GCI/R injury following OHCA, and the relative lack of effective neuroprotective strategies for this pathologic process, complement inhibition provides an exciting opportunity to augment existing treatment to improve patient outcomes. To this end, this paper will explore the pathophysiology of complementmediated GCI/R injury following OHCA.

\section{The Impact of out-of-Hospital Cardiac Arrest}

Heart disease remains the leading cause of mortality in the United States, and most frequently presents as sudden out-of-hospital cardiac arrest (OHCA) [9]. Recent sources indicate that approximately 166,000-310,000 Americans experience an OHCA per year [10], with a variable number 
undergoing resuscitation. Given this wide variability in reported incidence, survival and outcome following OHCA are difficult to accurately assess [9]. A multitude of factors has been shown to influence survival following OHCA, including demographic, clinical, and treatment factors [1119] and attempts at influencing those factors that are modifiable stand to potentially improve outcome. Brain injury from global cerebral ischemia-reperfusion is a major factor limiting the survival and functional recovery of patients after resuscitation from OHCA. In most cases, survivors have significant impairment of consciousness and may eventually progress to a persistent vegetative state [14]. The acute and long-term care for these survivors comes with a staggering cost to healthcare systems, patients' families, and society as a whole [20, 21].

Historically, survival following OHCA has been poor [22, 23 ], and although the morbidity and mortality of most cardiovascular diseases have declined over the last 30 years [10] there has been little improvement in survival post-OHCA $[24,25]$. Even in those patients that are resuscitated and survive the initial insult, crippling neurological deficits from the global cerebral ischemia experienced during the arrest are frequent. Survival for patients with an OHCA has been reported between 1 to $31 \%$ with significant regional variation $[9,10]$. In fact, a recent large, prospective, multicenter observational study throughout North America demonstrated that only $7.9 \%$ of treated cardiac arrest patients survive until discharge [9]. Multiple out-of-hospital factors, including bystander cardiopulmonary resuscitation (CPR), time to defibrillation, and EMS experience have all been associated with differences in survival after resuscitation [11, 26-28], yet the effect of hospital-based postresuscitation care on outcomes has been largely ignored.

With advances in EMS defibrillation programs, an increasing number of patients survive to hospital admission after OHCA. Of those patients, only $11-48 \%$ will be discharged from the hospital with good neurologic outcome [29]. Recently, in-hospital therapeutic hypothermia was established as an option to improve neurologic outcome after OHCA $[30,31]$. Another study suggested that hemofiltration to reduce inflammation after OHCA confers additional survival benefit, but this remains unproven [32].

\section{The Inflammatory Response following OHCA}

With arrest of systemic and cerebral blood flow for greater than 5 minutes, a series of events is initiated, inciting an inflammatory cascade resulting in significant cerebral injury $[9,10,23,33]$. During and after cardiopulmonary resuscitation, blood coagulation, platelet activation with formation of thromboxane $\mathrm{A}_{2}$, and an alteration of soluble E-selectin (sE-selectin) and P-selectin (sP-selectin) have been described [34-36]. A postresuscitation syndrome, characterized by hyperthermia, hypotension, and multiple organ failure is likely the clinical expression of whole-body ischemia-reperfusion (I/R) injury occurring after return of spontaneous circulation [32, 37]. This syndrome is associated with both complement activation and an intense increase of various inflammatory mediators (IL-1, IL-6, IL-8, and IL-10) as early as 3 hours after cardiac arrest, and thus affords potential targets for new treatments [37].

\section{Complement and Cerebral Ischemia}

The complement system, a phylogenetically conserved component of the innate immune system, has been shown to be significantly involved in ischemia-reperfusion injury in multiple organ systems, including the central nervous system (CNS). The complement cascade contains more than 20 proteins and is involved in inflammation, opsonization, and cytolysis in a wide range of diseases [38-44]. Complement activation refers to the process of complement cascade initiation and execution, which results in the production of inflammatory mediators (C3a, C5a), the opsonization of cells with components $(\mathrm{C} 3 \mathrm{~b})$ for recognition and phagocytosis by macrophages, and the formation of lethal membrane attack complexes (MAC, C5b-9) on target membranes [45].

Complement may be activated via one of several waysthe classical, alternative, and lectin pathways. The classical pathway is initiated by the binding of C1q to antibodyantigen complexes while the lectin pathway begins when pathogen-associated molecules become bound by lectin proteins, such as MBL. Both of these pathways then catalyze the cleavage of the $\mathrm{C} 2$ and $\mathrm{C} 4$ complement components which form a C3 convertase. Cleaved C3 then is incorporated into a C5 convertase which leads to the cleavage of C5 and the subsequent assembly of the MAC. The alternative pathway, however, relies on spontaneous hydrolysis of C3 to form C3 and $\mathrm{C} 5$ convertases which lead to the formation of the MAC. Also, there are several proteolytic enzymes such as elastases, kallikrein, and thrombin, which can cleave C3 or C5, directly [46-48] (Figure 1).

With regards to the central nervous system, activation of complement has been implicated in the pathophysiology of several distinct diseases, including multiple sclerosis [49], development of vasospasm following aneurysmal subarachnoid hemorrhage $[50,51]$, as well as stroke $[5,6,52]$.

Increasing evidence demonstrates that cerebral ischemia is followed by an acute systemic inflammatory response of the host. The complement system plays an essential and specific role in most pathological inflammatory events (upregulation of adhesion molecules, neutrophil activation, chemotaxis, expression of IL- 8 , and MCP-1 by endothelial cells) which occur shortly after the ischemic insult [53]. The essential role of complement activation in both microvascular failure and direct neuronal cell death was demonstrated in experimental animal models of permanent and transient middle cerebral artery occlusion (MCAO) through an increase in the expression of C3a and C5a receptors and presence of $\mathrm{C} 1 \mathrm{q}$ and $\mathrm{C} 3$ in the core of the infarct $[54,55]$. Our group subsequently demonstrated significant reduction of both infarct volume and oxidative stress after transient MCAO in C3 knock-out mice [6]. Furthermore, treatment of wild- type mice with C3a receptor antagonist ( $\mathrm{C} 3 \mathrm{aRA})$ resulted in reduced stroke volumes and improved neurologic function following transient cerebral ischemia [5, 6]. Recently, Arumugam et al. reported that C5-deficient mice were significantly protected from I/R 


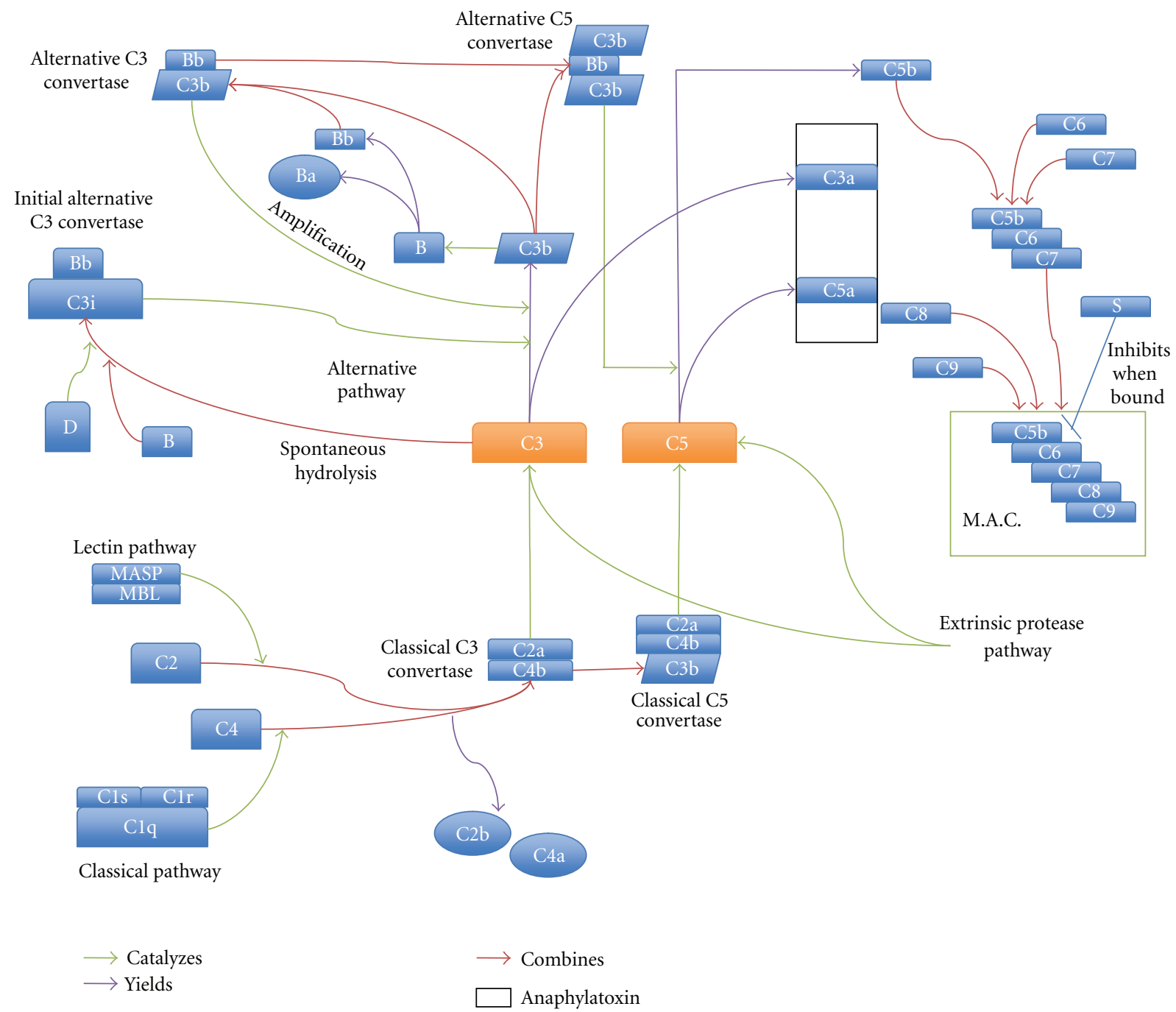

Figure 1: Complement cascade.

injury compared to wild-type littermates, and our group supported this data by demonstrating that $\mathrm{C} 5 \mathrm{a}$ receptor antagonism reduces infarction volume in mice $[56,57]$. In further rodent experiments, broad spectrum complement inhibitor cobra venom factor (CVF) $[8,56,58]$, intravenous immunoglobulin [56], C1-inhibitor [59, 60], and sCrry [61] have all been shown to be protective against experimental cerebral ischemia via complement inhibition.

Studies investigating complement activation following human cerebral ischemia have been more limited. Pederson et al. [54] and Mocco et al. [52] reported elevations of SC5b-9 and C3a, respectively, in human stroke patients. In a recent report, Szeplaki et al. further contributed to the body of knowledge regarding complement activation in cerebral ischemia by demonstrating early cleavage of multiple complement components and an association between degree of complement activation and clinical severity and unfavorable outcome [53]. There is also growing recognition that complement activation contributes to the pathogenesis of global hypoxic-ischemic (HI) injury in both rodent models and in human neonates. Circulating C3 is depleted following birth asphyxia, and it was recently demonstrated that pretreatment with CVF significantly reduced brain infarcts in $\mathrm{p} 7$ rats subjected to hypoxia-ischemia [45]. Additionally, Hedtjarn et al. noted that a number of genes involved in the complement system were induced by $\mathrm{HI}$ in the immature brain, including C3a receptor, C5a receptor, and C1q. Schultz et al. [62] also demonstrated significant upregulation of C9 in human infants who developed moderate to severe hypoxic-ischemic encephalopathy and experimental animal work by our group [7] demonstrated upregulation of $\mathrm{Clq}$ and $\mathrm{C} 3$ after an hypoxic-ischemic insult in mice. We further demonstrated significant protection in C1q knockout mice compared with wild-type littermates, highlighting the central role of the classical complement cascade in global cerebral hypoxicischemic injury. However distinct neonatal physiology may be, similar results have been found in studies of mature animals in regards to complement activation in the setting of transient global cerebral ischemia. Schafer et al. demonstrated early and widespread upregulation of $\mathrm{C} 1 \mathrm{q}$ expression 
in brain microglia and secretion of functionally active C1q into the CSF in response to experimentally induced global cerebral ischemia in rats [63].

\section{Ischemia/Reperfusion Injury following out-of-Hospital Cardiac Arrest}

Although reperfusion is essential for ultimate tissue survival, it may exacerbate cerebral injury and thus presents a treatment paradox [64]. As demonstrated above, activation of complement plays a critical role in ischemia-reperfusion injury leading to increased vascular permeability, activation of the coagulation cascade, free-radical production, and direct tissue damage $[3,65,66]$. Several models of ischemiareperfusion injury have implicated different complement activation pathways in this pathology, though less is known how these pathways are initiated in ischemia-reperfusion [7, 63, 67-71] (Table 1). Cardiac arrest and resuscitation represent a whole-body I/R syndrome [3], yet the role of complement in the pathophysiology of OHCA has only recently begun to be elucidated. Pretreatment with the proteinase inhibitor aprotinin and with heparin, both of which reduce complement activation [72], increases survival after cardiac arrest in rabbits [73]. In a swine model, aprotinin enhanced the recovery of cerebral energy metabolism after deep hypothermic circulatory arrest [74]. In the sole study looking at complement levels following OHCA in humans, Bottiger et al. demonstrated significant systemic upregulation of complement components C3a and SC5b-9 during cardiopulmonary resuscitation and early reperfusion after cardiac arrest [3]. The question remains, however, whether complement activation after cardiac arrest in humans is mechanistically involved with disease pathogenesis and impacts neurologic outcome following OHCA [3].

\section{Current Management of Global Cerebral Ischemia-Reperfusion Injury}

Recently, two trials demonstrated that induced hypothermia confers a neuroprotective effect in patients who were resuscitated from cardiac arrest $[30,31]$. Clinical and experimental results demonstrate a multifactorial neuroprotective effect of hypothermia during and after an ischemic insult by simultaneous suppression of several damaging pathways [29]. This has since become standard-of-care for select OHCA patients in centers where therapeutic hypothermia is offered. The proposed mechanism of hypothermia's protective effect has largely been attributed to its preservation of metabolic substrates, alteration of cerebral blood flow, and prevention of excitatory amino acid accumulation $[75,76]$. Other work, however, has shown that the profound effects of hypothermia on ameliorating cerebral injury are not fully explained by these factors. Some have thus proposed that mild hypothermia also has anti-inflammatory effects, although there are conflicting results in the literature [76-78]. Recently, in an elegantly designed rodent study, Callaway et al. demonstrated that hypothermia following cardiac arrest does not alter serum inflammatory markers, including TNF-alpha, MCP-1, IL-2, IL-9, and IL-10, suggesting that the beneficial effects
TABLE 1: Complement pathways in ischemia-reperfusion injury.

\begin{tabular}{|c|c|c|}
\hline Pathway & Type of I-R Injury & Study \\
\hline \multirow[t]{2}{*}{ Classical } & Brain & $\begin{array}{l}\text { Schäfer et al. [63], } \\
\text { Ten et al. [7] }\end{array}$ \\
\hline & Skeletal muscle & Weiser et al. [71] \\
\hline \multirow{2}{*}{ Alternative } & Gastrointestinal & Hart et al. [69] \\
\hline & Renal & $\begin{array}{l}\text { Thurman et al. [67], } \\
\text { Zhou et al. [70] }\end{array}$ \\
\hline \multirow{3}{*}{ Lectin } & Myocardial & Jordan et al. [68] \\
\hline & Gastrointestinal & Hart et al. [69] \\
\hline & Skeletal Muscle & Weiser et al. [71] \\
\hline
\end{tabular}

I-R: ischemia-reperfusion.

of hypothermia do not arise from attenuation of the inflammatory response [79]. Nevertheless, they confirmed a significant acute upregulation of inflammatory markers following ROSC. An alternate explanation is that the cerebral inflammatory response following cardiac arrest may not be accurately reflected in serum measurements of inflammatory biomarkers $[79,80]$. The findings detailed above raise the possibility of additional therapeutic benefit from targeted anticomplement and anti-inflammatory strategies combined with hypothermia in the setting of OHCA.

\section{Conclusion}

While there exists little data concerning the activation of complement in humans following OHCA, the importance of complement activation, and in particular $\mathrm{C} 3$, has been demonstrated repeatedly in the pathogenesis of ischemiareperfusion injury in both humans and various animal models [50, 51]. Selective complement inhibition, particularly of $\mathrm{C} 3$, is therefore an attractive strategy for global cerebral ischemia-reperfusion injury following OHCA, and may thereby improve long-term outcomes. While complement activation may be deleterious in the acute setting, it has been shown to be involved in modulation of neurogenesis, as well as the orderly clearance of apoptotic cell bodies, and therefore may have long-term beneficial effects [81]. As such, novel compounds that are able to reversibly inhibit downstream complement components, such as C3 and C3a, in the acute postischemic period may offer the best chance for a therapeutic benefit in human OHCA patients.

\section{References}

[1] P. Hillmen, N. S. Young, J. Schubert, et al., "The complement inhibitor eculizumab in paroxysmal nocturnal hemoglobinuria," The New England Journal of Medicine, vol. 355, no. 12, pp. 1233-1243, 2006.

[2] L. Testa, W. J. Van Gaal, R. Bhindi, et al., "Pexelizumab in ischemic heart disease: a systematic review and metaanalysis on 15,196 patients," The Journal of Thoracic and Cardiovascular Surgery, vol. 136, no. 4, pp. 884-893, 2008.

[3] B. W. Bottiger, J. Motsch, V. Braun, E. Martin, and M. Kirschfink, "Marked activation of complement and leukocytes and an increase in the concentrations of soluble endothelial 
adhesion molecules during cardiopulmonary resuscitation and early reperfusion after cardiac arrest in humans," Critical Care Medicine, vol. 30, no. 11, pp. 2473-2480, 2002.

[4] A. L. D'Ambrosio, D. J. Pinsky, and E. S. Connolly, "The role of the complement cascade in ischemia/reperfusion injury: implications for neuroprotection," Molecular Medicine, vol. 7, no. 6, pp. 367-382, 2001.

[5] A. F. Ducruet, B. G. Hassid, W. J. MacK, et al., "C3a receptor modulation of granulocyte infiltration after murine focal cerebral ischemia is reperfusion dependent," Journal of Cerebral Blood Flow and Metabolism, vol. 28, no. 5, pp. 1048$1058,2008$.

[6] J. Mocco, W. J. Mack, A. F. Ducruet, et al., "Complement component C3 mediates inflammatory injury following focal cerebral ischemia," Circulation Research, vol. 99, no. 2, pp. 209-217, 2006.

[7] V. S. Ten, S. A. Sosunov, S. P. Mazer, et al., "C1q-deficiency is neuroprotective against hypoxic-ischemic brain injury in neonatal mice," Stroke, vol. 36, no. 10, pp. 2244-2250, 2005.

[8] U. S. Vasthare, F. C. Barone, H. M. Sarau, et al., "Complement depletion improves neurological function in cerebral ischemia," Brain Research Bulletin, vol. 45, no. 4, pp. 413-419, 1998.

[9] G. Nichol, E. Thomas, C. W. Callaway, et al., "Regional variation in out-of-hospital cardiac arrest incidence and outcome," Journal of the American Medical Association, vol. 300, no. 12, pp. 1423-1431, 2008.

[10] W. Rosamond, K. Flegal, K. Furie, et al., "Heart disease and stroke statistics-2008 update: a report from the American Heart Association Statistics Committee and Stroke Statistics Subcommittee," Circulation, vol. 117, no. 4, pp. e25-e146, 2008.

[11] L. Bergner, M. Bergner, A. P. Hallstrom, M. S. Eisenberg, and L. A. Cobb, "Service factors and health status of survivors of out-of-hospital cardiac arrest," The American Journal of Emergency Medicine, vol. 1, no. 3, pp. 259-263, 1983.

[12] R. J. Fairbanks, M. N. Shah, E. B. Lerner, K. Ilangovan, E. C. Pennington, and S. M. Schneider, "Epidemiology and outcomes of out-of-hospital cardiac arrest in Rochester, New York," Resuscitation, vol. 72, no. 3, pp. 415-424, 2007.

[13] M. T. Froehler and R. G. Geocadin, "Hypothermia for neuroprotection after cardiac arrest: mechanisms, clinical trials and patient care," Journal of the Neurological Sciences, vol. 261, no. 1-2, pp. 118-126, 2007.

[14] R. G. Geocadin and S. M. Eleff, "Cardiac arrest resuscitation: neurologic prognostication and brain death," Current Opinion in Critical Care, vol. 14, no. 3, pp. 261-268, 2008.

[15] M. C. Geraghty and M. T. Torbey, "Neuroimaging and serologic markers of neurologic injury after cardiac arrest," Neurologic Clinics, vol. 24, no. 1, pp. 107-121, 2006.

[16] E. P. Hess, R. L. Campbell, and R. D. White, "Epidemiology, trends, and outcome of out-of-hospital cardiac arrest of noncardiac origin," Resuscitation, vol. 72, no. 2, pp. 200-206, 2007.

[17] H. A. Püttgen and R. Geocadin, "Predicting neurological outcome following cardiac arrest," Journal of the Neurological Sciences, vol. 261, no. 1-2, pp. 108-117, 2007.

[18] H. Rosén, K. Stibrant Sunnerhagen, J. Herlitz, C. Blomstrand, and L. Rosengren, "Serum levels of the brain-derived proteins S-100 and NSE predict long-term outcome after cardiac arrest," Resuscitation, vol. 49, no. 2, pp. 183-191, 2001.

[19] A. L. Sherman, D. L. Tirschwell, P. J. Micklesen, W. T. Longstreth Jr., and L. R. Robinson, "Somatosensory potentials, CSF creatine kinase BB activity, and awakening after cardiac arrest," Neurology, vol. 54, no. 4, pp. 889-894, 2000.
[20] W. A. Gray, R. J. Capone, and A. S. Most, "Unsuccessful emergency medical resuscitation-are continued efforts in the emergency department justified?" The New England Journal of Medicine, vol. 325, no. 20, pp. 1393-1398, 1991.

[21] M. B. Hamel, R. Phillips, J. Teno, et al., "Cost effectiveness of aggressive care for patients with nontraumatic coma," Critical Care Medicine, vol. 30, no. 6, pp. 1191-1196, 2002.

[22] M. S. Eisenberg and T. J. Mengert, "Cardiac resuscitation," The New England Journal of Medicine, vol. 344, no. 17, pp. 13041313, 2001.

[23] W. D. Rosamond, L. E. Chambless, A. R. Folsom, et al., "Trends in the incidence of myocardial infarction and in mortality due to coronary heart disease, 1987 to 1994," The New England Journal of Medicine, vol. 339, no. 13, pp. 861867, 1998.

[24] J. Herlitz, A. Bång, J. Gunnarsson, et al., "Factors associated with survival to hospital discharge among patients hospitalised alive after out of hospital cardiac arrest: change in outcome over 20 years in the community of Göteborg, Sweden," Heart, vol. 89, no. 1, pp. 25-30, 2003.

[25] T. D. Rea, R. M. Pearce, T. E. Raghunathan, et al., "Incidence of out-of-hospital cardiac arrest," American Journal of Cardiology, vol. 93, no. 12, pp. 1455-1460, 2004.

[26] F. Frandsen, J. R. Nielsen, L. Gram, C. F. Larsen, H. R. I. Jorgensen, and P. T. Hole Haghfelt, "Evaluation of intensified prehospital treatment in out-of-hospital cardiac arrest: survival and cerebral prognosis. The Odense ambulance study," Cardiology, vol. 79, no. 4, pp. 256-264, 1991.

[27] G. Nichol, I. G. Stiell, A. Laupacis, B. Pham, V. J. De Maio, and G. A. Wells, "A cumulative meta-analysis of the effectiveness of defibrillator-capable emergency medical services for victims of out-of-hospital cardiac arrest," Annals of Emergency Medicine, vol. 34, no. 4, part 1, pp. 517-525, 1999.

[28] J. G. van der Hoeven, J. de Koning, P. K. C. van der Weyden, and A. E. Meinders, "Improved outcome for patients with a cardiac arrest by supervision of the emergency medical services system," Netherlands Journal of Medicine, vol. 46, no. 3, pp. 123-130, 1995.

[29] M. Holzer, S. A. Bernard, S. Hachimi-Idrissi, R. O. Roine, F. Sterz, and M. Müllner, "Hypothermia for neuroprotection after cardiac arrest: systematic review and individual patient data meta-analysis," Critical Care Medicine, vol. 33, no. 2, pp. 414-418, 2005.

[30] M. Holzer, F. Sterz, J. M. Darby, et al., "Mild therapeutic hypothermia to improve the neurologic outcome after cardiac arrest," The New England Journal of Medicine, vol. 346, no. 8, pp. 549-556, 2002.

[31] S. A. Bernard, T. W. Gray, M. D. Buist, et al., "Treatment of comatose survivors of out-of-hospital cardiac arrest with induced hypothermia," The New England Journal of Medicine, vol. 346, no. 8, pp. 557-563, 2002.

[32] I. Laurent, C. Adrie, C. Vinsonneau, et al., "High-volume hemofiltration after out-of-hospital cardiac arrest: a randomized study," Journal of the American College of Cardiology, vol. 46, no. 3, pp. 432-437, 2005.

[33] V. A. Negovsky and A. M. Gurvitch, "Post-resuscitation disease-a new nosological entity. Its reality and significance," Resuscitation, vol. 30, no. 1, pp. 23-27, 1995.

[34] S. Gando, S. Nanzaki, Y. Morimoto, S. Kobayashi, and O. Kemmotsu, "Alterations of soluble L- and P-selectins during cardiac arrest and CPR," Intensive Care Medicine, vol. 25, no. 6, pp. 588-593, 1999. 
[35] S. Gando, S. Nanzaki, Y. Morimoto, S. Kobayashi, and O. Kemmotsu, "Out-of-hospital cardiac arrest increases soluble vascular endothelial adhesion molecules and neutrophil elastase associated with endothelial injury," Intensive Care Medicine, vol. 26, no. 1, pp. 38-44, 2000.

[36] A. Geppert, G. Zorn, G. Delle-Karth, et al., "Plasma concentrations of von Willebrand factor and intracellular adhesion molecule-1 for prediction of outcome after successful cardiopulmonary resuscitation," Critical Care Medicine, vol. 31, no. 3, pp. 805-811, 2003.

[37] C. Adrie, M. Adib-Conquy, I. Laurent, et al., "Successful cardiopulmonary resuscitation after cardiac arrest as a "sepsislike” syndrome," Circulation, vol. 106, no. 5, pp. 562-568, 2002.

[38] R. E. Chavez-Cartaya, G. P. DeSola, L. Wright, N. V. Jamieson, and D. J. G. White, "Regulation of the complement cascade by soluble complement receptor type 1: protective effect in experimental liver ischemia and reperfusion," Transplantation, vol. 59, no. 7, pp. 1047-1052, 1995.

[39] K. E. Foreman, M. M. Glovsky, R. L. Warner, S. J. Horvath, and P. A. Ward, "Comparative effect of C3a and C5a on adhesion molecule expression on neutrophils and endothelial cells," Inflammation, vol. 20, no. 1, pp. 1-9, 1996.

[40] J. Hill, T. F. Lindsay, F. Ortiz, C. G. Yeh, H. B. Hechtman, and F. D. Moore Jr., "Soluble complement receptor type 1 ameliorates the local and remote organ injury after intestinal ischemia-reperfusion in the rat," The Journal of Immunology, vol. 149, no. 5, pp. 1723-1728, 1992.

[41] J. H. Hill and P. A. Ward, "The phlogistic role of C3 leukotactic fragments in myocardial infarcts of rats.," Journal of Experimental Medicine, vol. 133, no. 4, pp. 885-900, 1971.

[42] M. Ikai, M. Itoh, T. Joh, Y. Yokoyama, N. Okada, and H. Okada, "Complement plays an essential role in shock following intestinal ischaemia in rats," Clinical \& Experimental Immunology, vol. 106, no. 1, pp. 156-159, 1996.

[43] M. Pemberton, G. L. Anderson, V. Vetvicka, D. E. Justus, and G. D. Ross, "Microvascular effects of complement blockade with soluble recombinant CR1 on ischemia/reperfusion injury of skeletal muscle," The Journal of Immunology, vol. 150, no. 11, pp. 5104-5113, 1993.

[44] M. R. Zamora, R. D. Davis, S. H. Keshavjee, et al., "Complement inhibition attenuates human lung transplant reperfusion injury: a multicenter trial," Chest, vol. 116, supplement 1, p. 46S, 1999.

[45] R. M. Cowell, J. M. Plane, and F. S. Silverstein, "Complement activation contributes to hypoxic-ischemic brain injury in neonatal rats," Journal of Neuroscience, vol. 23, no. 28, pp. 9459-9468, 2003.

[46] W. Vogt, B. Damerau, and B. Luhmann, "Complement activation in human lymph: modulation by the contact activation system and by leukocytes," International Archives of Allergy and Applied Immunology, vol. 79, no. 4, pp. 423-433, 1986.

[47] M. Huber-Lang, J. V. Sarma, F. S. Zetoune, et al., "Generation of C5a in the absence of C3: a new complement activation pathway," Nature Medicine, vol. 12, no. 6, pp. 682-687, 2006.

[48] R. C. Wiggins, P. C. Giclas, and P. M. Henson, "Chemotactic activity generated from the fifth component of complement by plasma kallikrein of the rabbit," Journal of Experimental Medicine, vol. 153, no. 6, pp. 1391-1404, 1981.

[49] P. Gasque, S. K. Singhrao, J. W. Neal, et al., "The receptor for complement anaphylatoxin $\mathrm{C} 3 \mathrm{a}$ is expressed by myeloid cells and nonmyeloid cells in inflamed human central nervous system: analysis in multiple sclerosis and bacterial meningitis," The Journal of Immunology, vol. 160, no. 7, pp. 3543-3554, 1998.
[50] H. Kasuya and T. Shimizu, "Activated complement components C3a and C4a in cerebrospinal fluid and plasma following subarachnoid hemorrhage," Journal of Neurosurgery, vol. 71, no. 5, part 1, pp. 741-746, 1989.

[51] W. J. Mack, A. F. Ducruet, Z. L. Hickman, et al., "Early plasma complement C3a levels correlate with functional outcome after aneurysmal subarachnoid hemorrhage," Neurosurgery, vol. 61, no. 2, pp. 255-260, 2007.

[52] J. Mocco, D. A. Wilson, R. J. Komotar, et al., "Alterations in plasma complement levels after human ischemic stroke," Neurosurgery, vol. 59, no. 1, pp. 28-32, 2006.

[53] G. Széplaki, R. Szegedi, K. Hirschberg, et al., "Strong complement activation after acute ischemic stroke is associated with unfavorable outcomes," Atherosclerosis, vol. 204, no. 1, pp. 315-320, 2009.

[54] E. D. Pedersen, U. Waje-Andreassen, C. A. Vedeler, G. Aamodt, and T. E. Mollnes, "Systemic complement activation following human acute ischaemic stroke," Clinical \& Experimental Immunology, vol. 137, no. 1, pp. 117-122, 2004.

[55] J. Van Beek, M. Bernaudin, E. Petit, et al., "Expression of receptors for complement anaphylatoxins C3a and C5a following permanent focal cerebral ischemia in the mouse," Experimental Neurology, vol. 161, no. 1, pp. 373-382, 2000.

[56] T. V. Arumugam, S.-C. Tang, J. D. Lathia, et al., "Intravenous immunoglobulin (IVIG) protects the brain against experimental stroke by preventing complement-mediated neuronal cell death," Proceedings of the National Academy of Sciences of the United States of America, vol. 104, no. 35, pp. 14104-14109, 2007.

[57] G. H. Kim, J. Mocco, D. K. Hahn, et al., "Protective effect of C5a receptor inhibition after murine reperfused stroke," Neurosurgery, vol. 63, no. 1, pp. 122-125, 2008.

[58] E. Figueroa, L. E. Gordon, P. W. Feldhoff, and H. A. Lassiter, "The administration of cobra venom factor reduces post-ischemic cerebral injury in adult and neonatal rats," Neuroscience Letters, vol. 380, no. 1-2, pp. 48-53, 2005.

[59] N. Akita, H. Nakase, T. Kaido, et al., "Protective effect of $\mathrm{C} 1$ esterase inhibitor on reperfusion injury in the rat middle cerebral artery occlusion model," Neurosurgery, vol. 52, no. 2, pp. 395-401, 2003.

[60] M. G. De Simoni, C. Storini, M. Barba, et al., "Neuroprotection by complement $(\mathrm{C} 1)$ inhibitor in mouse transient brain ischemia," Journal of Cerebral Blood Flow and Metabolism, vol. 23, no. 2, pp. 232-239, 2003.

[61] C. Atkinson, H. Zhu, F. Qiao, et al., "Complement-dependent P-selectin expression and injury following ischemic stroke," The Journal of Immunology, vol. 177, no. 10, pp. 7266-7274, 2006.

[62] S. J. Schultz, H. Aly, B. M. Hasanen, et al., "Complement component 9 activation, consumption, and neuronal deposition in the post-hypoxic-ischemic central nervous system of human newborn infants," Neuroscience Letters, vol. 378, no. 1, pp. 16, 2005.

[63] M. K.-H. Schäfer, W. J. Schwaeble, C. Post, et al., "Complement $\mathrm{Clq}$ is dramatically up-regulated in brain microglia in response to transient global cerebral ischemia," The Journal of Immunology, vol. 164, no. 10, pp. 5446-5452, 2000.

[64] P. Safar, W. Behringer, B. W. Böttiger, and F. Sterz, "Cerebral resuscitation potentials for cardiac arrest," Critical Care Medicine, vol. 30, no. 4, supplement, pp. S140-S144, 2002.

[65] M. H. Crawford, F. L. Grover, W. P. Kolb, et al., "Complement and neutrophil activation in the pathogenesis of ischemic myocardial injury," Circulation, vol. 78, no. 6, pp. 1449-1458, 1988. 
[66] J. W. Homeister, P. Satoh, and B. R. Lucchesi, "Effects of complement activation in the isolated heart: role of the terminal complement components," Circulation Research, vol. 71, no. 2, pp. 303-319, 1992.

[67] J. M. Thurman, D. Ljubanovic, C. L. Edelstein, G. S. Gilkeson, and V. M. Holers, "Lack of a functional alternative complement pathway ameliorates ischemic acute renal failure in mice," The Journal of Immunology, vol. 170, no. 3, pp. 1517 1523, 2003.

[68] J. E. Jordan, M. C. Montalto, and G. L. Stahl, "Inhibition of mannose-binding lectin reduces postischemic myocardial reperfusion injury," Circulation, vol. 104, no. 12, pp. 1413$1418,2001$.

[69] M. L. Hart, M. C. Walsh, and G. L. Stahl, "Initiation of complement activation following oxidative stress. In vitro and in vivo observations," Molecular Immunology, vol. 41, no. 2-3, pp. 165-171, 2004.

[70] W. Zhou, C. A. Farrar, K. Abe, et al., "Predominant role for C5b-9 in renal ischemia/reperfusion injury," The Journal of Clinical Investigation, vol. 105, no. 10, pp. 1363-1371, 2000.

[71] M. R. Weiser, J. P. Williams, F. D. Moore Jr., et al., "Reperfusion injury of ischemic skeletal muscle is mediated by natural antibody and complement," Journal of Experimental Medicine, vol. 183, no. 5, pp. 2343-2348, 1996.

[72] J. M. Weiler, R. E. Edens, R. J. Linhardt, and D. P. Kapelanski, "Heparin and modified heparin inhibit complement activation in vivo," The Journal of Immunology, vol. 148, no. 10, pp. 3210-3215, 1992.

[73] W. Gaszynski, "The use of protease inhibitor (trasylol) and heparin in cardiorespiratory resuscitation. I. Studies of the blood clotting system," Anaesthesia Resuscitation and Intensive Therapy, vol. 3, no. 2, pp. 125-134, 1975.

[74] M. Aoki, R. A. Jonas, F. Nomura, et al., "Effects of aprotinin on acute recovery of cerebral metabolism in piglets after hypothermic circulatory arrest," Annals of Thoracic Surgery, vol. 58, no. 1, pp. 146-153, 1994.

[75] R. Busto, M. Y.-T. Globus, W. D. Dietrich, E. Martinez, I. Valdes, and M. D. Ginsberg, "Effect of mild hypothermia on ischemia-induced release of neurotransmitters and free fatty acids in rat brain," Stroke, vol. 20, no. 7, pp. 904-910, 1989.

[76] M. A. Yenari and H. S. Han, "Influence of hypothermia on post-ischemic inflammation: role of nuclear factor kappa B (NFkB)," Neurochemistry International, vol. 49, no. 2, pp. 164169, 2006.

[77] J. Inamasu, S. Suga, S. Sato, et al., "Post-ischemic hypothermia delayed neutrophil accumulation and microglial activation following transient focal ischemia in rats," Journal of Neuroimmunology, vol. 109, no. 2, pp. 66-74, 2000.

[78] J. Inamasu, S. Suga, S. Sato, et al., "Intra-ischemic hypothermia attenuates intercellular adhesion molecule-1 (ICAM-1) and migration of neutrophil," Neurological Research, vol. 23, no. 1, pp. 105-111, 2001.

[79] C. W. Callaway, J. C. Rittenberger, E. S. Logue, and M. J. McMichael, "Hypothermia after cardiac arrest does not alter serum inflammatory markers," Critical Care Medicine, vol. 36, no. 9, pp. 2607-2612, 2008.

[80] A. I. Qureshi, "Serum inflammatory markers after postcardiac arrest resuscitation: surrogate markers of efficacy, therapeutic targets, or innocent bystanders," Critical Care Medicine, vol. 36, no. 9, pp. 2698-2699, 2008.

[81] Y. Rahpeymai, M. A. Hietala, U. Wilhelmsson, et al., "Complement: a novel factor in basal and ischemia-induced neurogenesis," EMBO Journal, vol. 25, no. 6, pp. 1364-1374, 2006. 


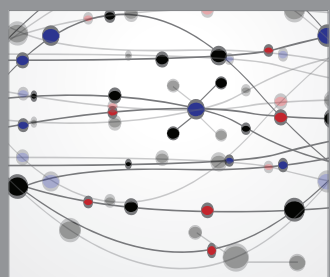

The Scientific World Journal
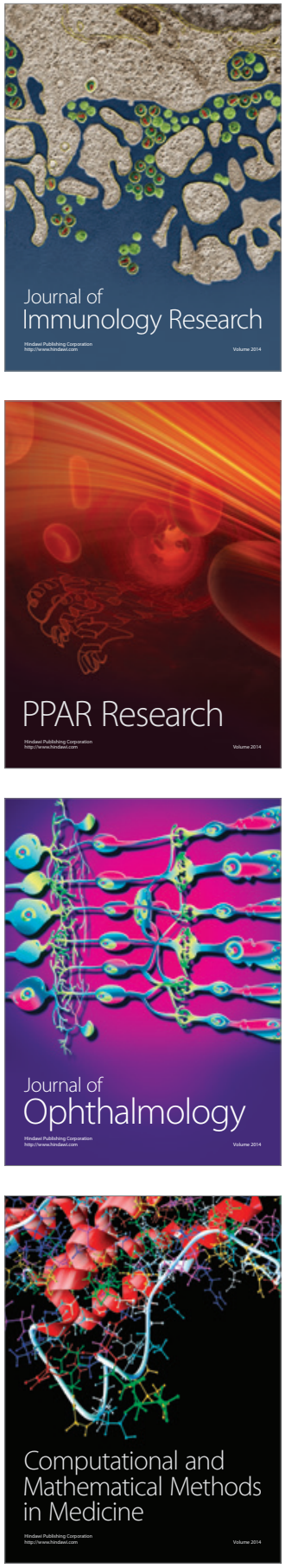

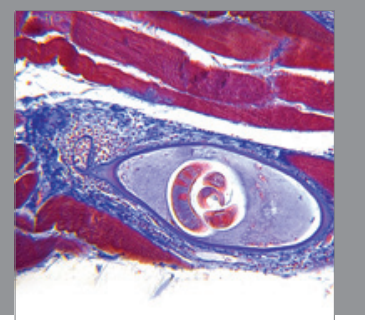

Gastroenterology

Research and Practice
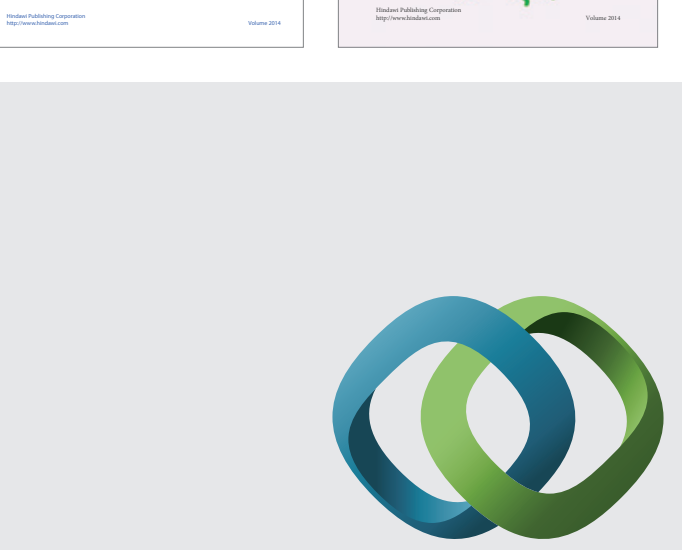

\section{Hindawi}

Submit your manuscripts at

http://www.hindawi.com
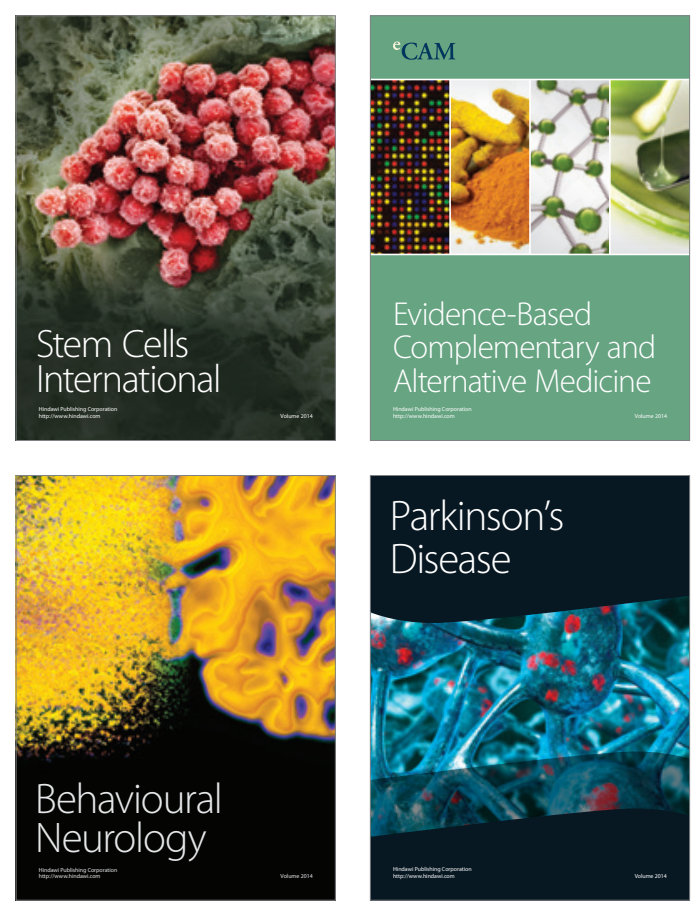

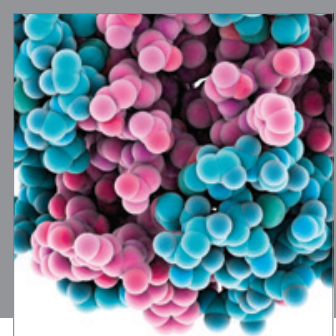

Journal of
Diabetes Research

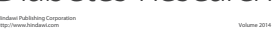

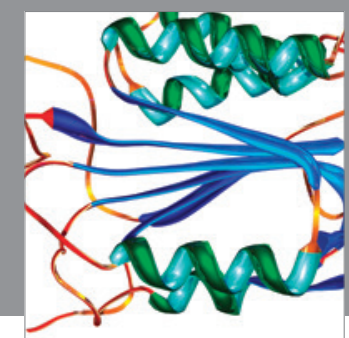

Disease Markers
